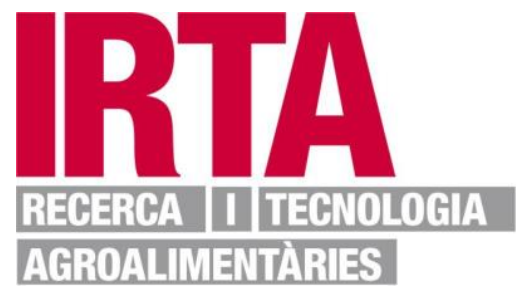

This document is a postprint version of an article published in Agricultural and Forest Meteorology@ Elsevier after peer review. To access the final edited and published work see https://doi.org/10.1016/_.agrformet.2019.107776

Document downloaded from: 


\section{Studying and modelling winter dormancy in olive trees}

2 Álvaro López-Bernal ${ }^{1, *}$, Omar García-Tejera ${ }^{2}$, Luca Testi $^{3}$, Francisco Orgaz $^{3}$, Francisco

3 J. Villalobos ${ }^{1,3}$

$4{ }^{1}$ Departmento de Agronomia, Univ. of Cordoba, Campus de Rabanales, Edificio C4, 5 14071, Cordoba, Spain

$6 \quad{ }^{2}$ Efficient Use of Water Program, Institut de Recerca i Tecnologia Agroalimentàries

7 (IRTA), Parc de Gardeny, Edifici Fruitcentre, 25003, Lleida, Spain

$8 \quad{ }^{3}$ Institute for Sustainable Agriculture (IAS), Spanish Research Council (CSIC), Av.

9 Menéndez Pidal s/n, 14080, Cordoba, Spain

10 *Corresponding author: g42lobea@uco.es

12 Published in Agricultural and Forest Meteorology (2020) 280: 107776

13 doi.org/10.1016/j.agrformet.2019.107776 
- Low autumn temperatures induce growth cessation in shoot apical meristems of olive

- The subsequent dormant state is easily reversed after the exposure to warm conditions

- Growth rate upon budbreak is related to the length of the preceding dormant period

- Cultivar differences in the onset of winter dormancy are small

- Two simple models for predicting the onset of dormancy are presented and

23 tested 


\section{Abstract}

47 Keywords: dormancy, growth cessation, Olea europaea L, phenology, photoperiod,

The abundance of scientific papers dealing with olive reproductive phenology contrasts with the scarce information available in relation to the winter dormant state of olive vegetative structures. In this study, three experiments with young olive trees were performed in Southern Spain, aiming to provide insight into some features of the winter rest period in this evergreen species. Experiment 1 evaluated the environmental cues triggering dormancy induction by measuring leaf appearance rates in trees subjected to different conditions of temperature and daylength over the course of the 2012 autumn. In Experiment 2, several sets of plants were placed into a greenhouse at different dates along the 2013/2014 winter, testing the ability of dormant plants to resume growth upon the return of favorable temperatures. Finally, Experiment 3 was carried out during the autumns of 2016 and 2017 in two locations, and was devoted to assess differences between five cultivars in the onset of dormancy under natural conditions. Our findings revealed that dormancy induction is not controlled by photoperiod, but by low temperatures. The subsequent winter rest state seems to be easily reversed after 1-2 weeks of exposure to warm conditions, irrespective of the initial date of exposure. With regard to cultivar variability, differences in the timing of growth cessation was found to be rather small. Finally, two simple models for predicting the onset of dormancy based on the accumulation of a certain amount of chilling (either considering or not a reversal of chilling by warm temperatures) are presented. Calibration and validation was performed with independent datasets from Experiments 1, 2 and 3. Validation tests highlighted the reliability of both models in reproducing the date of growth cessation. temperature, vegetative growth 


\section{Introduction}

Olive orchards represent an extensive cropping system that covers more than 10 Mha worldwide (FAOSFAT, 2017). In this evergreen tree, fruit-producing inflorescences develop from axillary buds of the leaves of the previous year shoots (Rapoport and Moreno-Alías, 2017). However, reproductive budburst does not proceed satisfactorily unless sufficient chilling occurs during the winter. This fact explains why the introduction of the olive crop has achieved limited success in warm equatorial regions such as Florida, Texas, Guatemala or Hawaii (Hartmann, 1953; Miyasaka and Hamasaki, 2016). On the other hand, the survival of olive trees is compromised in regions where temperatures drop below $-12^{\circ} \mathrm{C}$ (Barranco et al., 2005; Larcher, 1970). These constraints determine that olive plantations are usually between latitudes $30^{\circ}$ and $45^{\circ}$.

In most of the regions where olives are cultivated, trees cease their vegetative growth in autumn and undergo a winter rest period lasting until favorable temperature conditions return in early spring. The acquisition of this dormant state seems to be essential to increase freezing tolerance, as it is the case for many perennial species (Arora et al., 2003; van der Schoot and Rinne, 2011), and coincides with the period during which the chilling requirement for flower initiation in the axillary buds is fulfilled. In the last decades, substantial research efforts have been devoted to understand the critical factors promoting flower induction and reproductive budburst in axillary buds (Haberman et al., 2017; Rallo and Martin, 1991; Ramos et al., 2018) and to develop simulation models for predicting the date of flowering (De Melo-Abreu et al., 2004). This rather large body of literature contrast with the lack of information available in relation to the essential characteristics of the winter dormant state of olive vegetative structures and its governing environmental cues. 
73 Studying the signals controlling the duration of the vegetative dormant state undergone

74 by olive trees during winter is important because of the implications for the carbon balance of trees. Being an evergreen species, the photosynthetic activity of olive leaves does not stop during winter, so the produced assimilates are stored in several tissues. Following bud break, the stored carbohydrates are partly invested in the growth of vegetative and reproductive structures (Bustan et al., 2011). Although we do not know yet if the reserve pool acts as an active sink of carbohydrates, it seems clear that the duration of the winter dormant period might have a significant impact on the carbon partitioning among the different organs and, probably, on tree productivity. Apart from that, predicting the timing of bud break might be useful for crop management decisions like the application of agrochemicals.

Past experiences in which olive trees were introduced in low latitude regions indicate that, contrary to reproductive development, vegetative growth proceeds satisfactorily throughout the whole season without any winter chilling (Hartmann, 1953; Hartmann and Porlingis, 1957). Apart from those indirect and scattered observations, the only scientific paper dealing with the effect of winter chilling on olive vegetative growth is the one by Hartmann (1953). Working in California, this author measured trunk growth and shoot length in various sets of olive plants that were exposed to different levels of winter chilling by placing the plants inside a warm greenhouse at different dates. Experimental results again showed that the longer the period under warm temperatures, the higher the vegetative growth. Nevertheless, Hartmann (1953) found a period of negligible growth during January even in the case of plants that were kept under greenhouse conditions the whole winter, which could be indicative of a slight vegetative rest period triggered by short photoperiod. 
97 The objectives of this study were: 1) to identify which environmental cues (low temperature, short photoperiod or an interaction between both) lead to the induction of vegetative dormancy in winter, 2) to test whether vegetative growth can resume instantaneously upon the return of favorable conditions (ecodormancy) or if it is impeded endogenously (endodormancy), 3) to explore differences in the onset of winter dormancy between five olive cultivars and 4) to formulate and test simple models for predicting the start of the winter rest period.

\section{Materials and Methods}

\subsection{Experiment 1}

The aim of Experiment 1 was to ascertain the role of temperature and photoperiod in the onset of winter dormancy. Fifteen 2-year-old cv. 'Arbequina' trees growing in $25 \mathrm{~L}$ pots filled with a mixture of sand, silt and peat moss were used. The experiment was executed from September to December of 2012. At the start of the experiment, fruits were removed manually and $2 \mathrm{~g} \mathrm{~L}^{-1}$ of a complex slow-release fertilizer was applied. Irrigation was supplied daily throughout the experiment, with the dose being adjusted to avoid excessive drainage while maintaining soil water content close to field capacity.

Those individuals were randomly grouped in five sets of three plants, each of them receiving a different treatment during the experiment. The five treatments consisted of:

- Negative control (NC): plants were kept outdoors under natural conditions of temperature and photoperiod at the Institute for Sustainable Agriculture (IASCSIC) in Cordoba, Spain $\left(37.8^{\circ} \mathrm{N}, 4.8^{\circ} \mathrm{W}, 130 \mathrm{~m}\right)$.

- Limited temperature 1 (LT1): plants were carried to "Finca Villazulina" in Espiel, Spain $\left(38.3^{\circ} \mathrm{N}, 5.0^{\circ} \mathrm{W}, 580 \mathrm{~m}\right)$, where they were kept outdoors under natural 
conditions of temperature and photoperiod. Being located some $40 \mathrm{~km}$ to the Northwest of Cordoba in the mountain range of Sierra Morena, Espiel presents lower temperatures than Cordoba with the same photoperiod.

- $\quad$ Limited temperature 2 (LT2): plants were kept outdoors at the IAS-CSIC, as those of the NC treatment, but the natural photoperiod was artificially extended to $14 \mathrm{~h}$. To do so, incandescent lamps were placed $0.5 \mathrm{~m}$ above the plants and programmed to supply light from 6.00 to 9.00 GMT and from 16.00 to 19.00 GMT every day. - Limited photoperiod (LP): plants were kept in a growth chamber at the IAS-CSIC facilities. Temperature and photoperiod were maintained constant throughout the experiment at $20^{\circ} \mathrm{C}$ and $10 \mathrm{~h}$, respectively.

- Positive control (PC): plants were kept in a greenhouse with artificial lighting at the IAS-CSIC facilities. Photoperiod was fixed to $14 \mathrm{~h}$ while a heating system was automatically controlled to keep temperature above $18^{\circ} \mathrm{C}$.

During the experiment, an automated weather station in each location monitored the main meteorological variables throughout the experiment for the outdoor treatments. In LP and PC, temperatures were measured in the growth chamber and the greenhouse, respectively using temperature data loggers (MicroLite, Fourier Technologies).

Estimates of vegetative growth were performed by determining the rate of appearance of new leaf pairs in healthy sun-exposed marked shoots. In the selection of the sample shoots, it was checked that they were actively growing. Three shoots per plant (i.e. nine shoots per treatment) were selected for the measurements, which consisted of counting the number of leaf pairs in each shoot every week. Near the shoot tip, incipient leaf pairs were not counted unless the length of the limbs was higher than $5 \mathrm{~mm}$. Albeit infrequent (just two cases in Experiment 1), new shoots formed from the sprouting of axillary buds 
145 in marked shoots were not considered as new growth for the parent shoot, as the experiment was aimed to monitor the activity of shoot apical meristems.

The goal of Experiment 2 was to test whether the vegetative winter rest of olive trees is due to endodormancy or ecodormancy. The experiment was carried out at the IAS-CSIC from October 2013 to March 2014 with 1-year-old cv. 'Arbequina' trees growing in plastic bags ( $30 \mathrm{~cm}$ long, $15 \mathrm{~cm}$ diameter, with drainage holes). All plants (30 individuals) were initially grown under natural outdoor conditions. Three healthy shoots were marked in seven individuals and the vegetative activity of their apical meristems was monitored weekly by counting the number of new leaf pairs, as in Experiment 1. Once leaf appearance ceased in all the monitored shoots by late autumn, sets of three plants were transferred during the winter at different dates ( 8 sets of plants in total) to a greenhouse in which the minimum temperature was maintained above $18^{\circ} \mathrm{C}$. Namely, the entry dates were, November 25 (day of year-DOY-329), December 11 (DOY 345), December 20 (DOY 354), January 2 (DOY 2), January 13 (DOY 13), January 27 (DOY 27), February 10 (DOY 41) and March 6 (DOY 65). Following their entry into the greenhouse, the weekly monitoring of marked shoots (three shoots per plant, totaling nine shoots per set of plants) was used to identify differences between sets of plants in the time required for growth resumption and, subsequently, in the rate of leaf generation. The remaining potted controls. All plants in the greenhouse and outdoors were exposed to the natural photoperiod 
In this experiment differences between olive cultivars in the onset of winter dormancy were studied. The experiment was performed in Cordoba and Espiel during the autumns of 2016 and 2017 with five olive cultivars: 'Picual', 'Arbequina', 'Hojiblanca',

173 'Cornicabra' and 'Cobrançosa'. The plants, grown in $25 \mathrm{~L}$ pots filled with a mixture of sand, silt and peat, were 2-year-old at the start of the experiments and maintained under appropriate growing conditions throughout the two complete years by applying irrigation and slow-release fertilizers. Each year, prior to the start of the measurements, fruits were removed manually. The main meteorological variables were recorded throughout the experiment with automated weather stations in the two locations.

Two or three individuals per cultivar and location were used for the 2016 and 2017 autumns, respectively. Five (2016) and seven (2017) healthy shoots per tree were selected for the measurements, which consisted of counting the number of leaf pairs in each shoot every week, as in the previous experiments.

For assessing cultivar differences in the onset of dormancy, an analysis of variance (ANOVA) was performed for each dataset considering each shoot as an experimental unit and the date at which the last pair of leaves were generated as the experimental variable. Mean comparisons were conducted using the Tukey HSD test. For one dataset (Espiel 2016), the normality of the variance requisite was not satisfied and the Kruskal-Wallis test was used, being the mean comparisons performed with the Dunn's test. The null hypothesis (i.e. no cultivar-differences in the date of the onset of dormancy) was rejected when $\mathrm{P}$ values were below 0.05 . All the statistical analyses were performed with Statistix (Statistix 10 for Windows, Analytical Software, Tallahassee, FL, USA). 
194 Two models were tested for predicting the date of growth cessation. The first (Model 1) considers that the onset of dormancy occurs whenever enough chilling $\left(\Sigma U_{\mathrm{c}}\right)$ is accumulated, computing such chilling as the number of hours with temperatures below a

197 given threshold. The second (Model 2) is a further development of the former that considers that hourly temperatures above the temperature threshold for chilling accumulation result in a partial reversal of the chilling accumulated so far.

For both models, hourly temperature records are input to the model, with the accumulation of chilling $(U)$ during $1 \mathrm{~h}$ being:

202

$U=\left\{\begin{array}{ll}1 & \text { if } T<T_{c} \\ a & \text { if } T>T_{c}\end{array}\right\}(1)$

Where $T$ is the hourly air temperature $\left({ }^{\circ} \mathrm{C}\right), T_{c}$ is the threshold temperature for chilling accumulation/reversal $\left({ }^{\circ} \mathrm{C}\right)$ and $a$ is parameter with a negative value representing the number of chilling units that are lost for each hour of high temperature following a chilling accumulation period. In Model 1 the value of $a$ is forced to 0. Chilling accumulation is assumed to start on 1 September and all negative values of this accumulation are discarded so that the condition $\Sigma U \geq 0$ is always satisfied.

Hourly temperature records and the dates of growth cessation for $50 \%$ of the monitored shoots collected for plants of the cultivar 'Arbequina' growing under natural conditions in Cordoba in 2012, 2013, 2016 and 2017 (Experiments 1, 2 and 3) were used for 212 calibration. The values of $T_{\mathrm{c}}, \Sigma U_{\mathrm{c}}$ and $a$ were fitted by minimizing the root mean square error (RMSE) of model predictions Then, model validation was performed with data collected in Espiel in 2012, 2016 and 2017 (experiments 1 and 3). Model performances in reproducing measured data were assessed using mean absolute error (MAE, from 0 to 
$+\infty$, optimum 0 ), coefficient of residual mass (CRM, from $-\infty$ to $+\infty$, optimum 0 ) and modelling efficiency (EF, from $-\infty$ to 1 , optimum 1$)$.

\subsection{Additional analysis}

Data collected in the three experiments corresponding to the 'Arbequina' cultivar growing under undisturbed outdoor conditions were used to explore the relationships between leaf appearance rates and temperature. Using only the data corresponding to periods with active growth (establishing a threshold of 0.05 leaf pairs week ${ }^{-1} \operatorname{shoot}^{-1}$ ), a linear regression analysis was used to estimate the base temperature and phyllochron (i.e. the thermal time between the appearance of consecutive leaf pairs). This analysis is completely independent from the modelling approaches indicated in the previous section.

\section{Results}

\subsection{Experiment 1}

The meteorological conditions recorded during the experiment were typical of autumn in the study area; apart from a rather high cumulative rainfall in relation to an average year (386 $\mathrm{mm}$ and $341 \mathrm{~mm}$ were recorded between September $1^{\text {st }}$ (DOY 245) and November 30 (DOY 335) in Cordoba and Espiel, respectively). As usual, temperatures decreased as autumn progressed. Those patterns were similar for the two experimental sites, but temperatures were, on average, $3{ }^{\circ} \mathrm{C}$ lower in Espiel than in Cordoba. This is illustrated in Figure 1A, which also plots the temperature measured in both the growth chamber and the greenhouse, where the indoor treatments were applied. In this regard, PC plants were under higher temperatures than NC throughout the experiment, while LP individuals were subjected to temperatures always close to $20^{\circ} \mathrm{C}$, as intended. 
240 Figure 1B presents the time course of the estimates of vegetative growth for the five

241 treatments. While the appearance of new leaf pairs in NC, LT1 and LT2 ceased

242 completely before the end of the experiment, the indoor treatments (i.e. PC and LP),

243 which were never below $18{ }^{\circ} \mathrm{C}$, did not stop growing. Noticeably, the arrest of growth

244 occurred several weeks earlier in LT1 than in NC and LT2, for which the estimates of

245 growth rates became negligible by the second half of November (ca. DOY 330).

246 However, it must be highlighted that there was considerable variability in the behavior

247 between the monitored shoots of each treatment. In this regard, differences of up to one

248 month in the date of the last observation of growth were found between the shoots of NC

249 and between those of LT2 (Fig. 2). In the case of LT1, the variability in the date of growth

250 cessation was smaller. 
Day of 2012
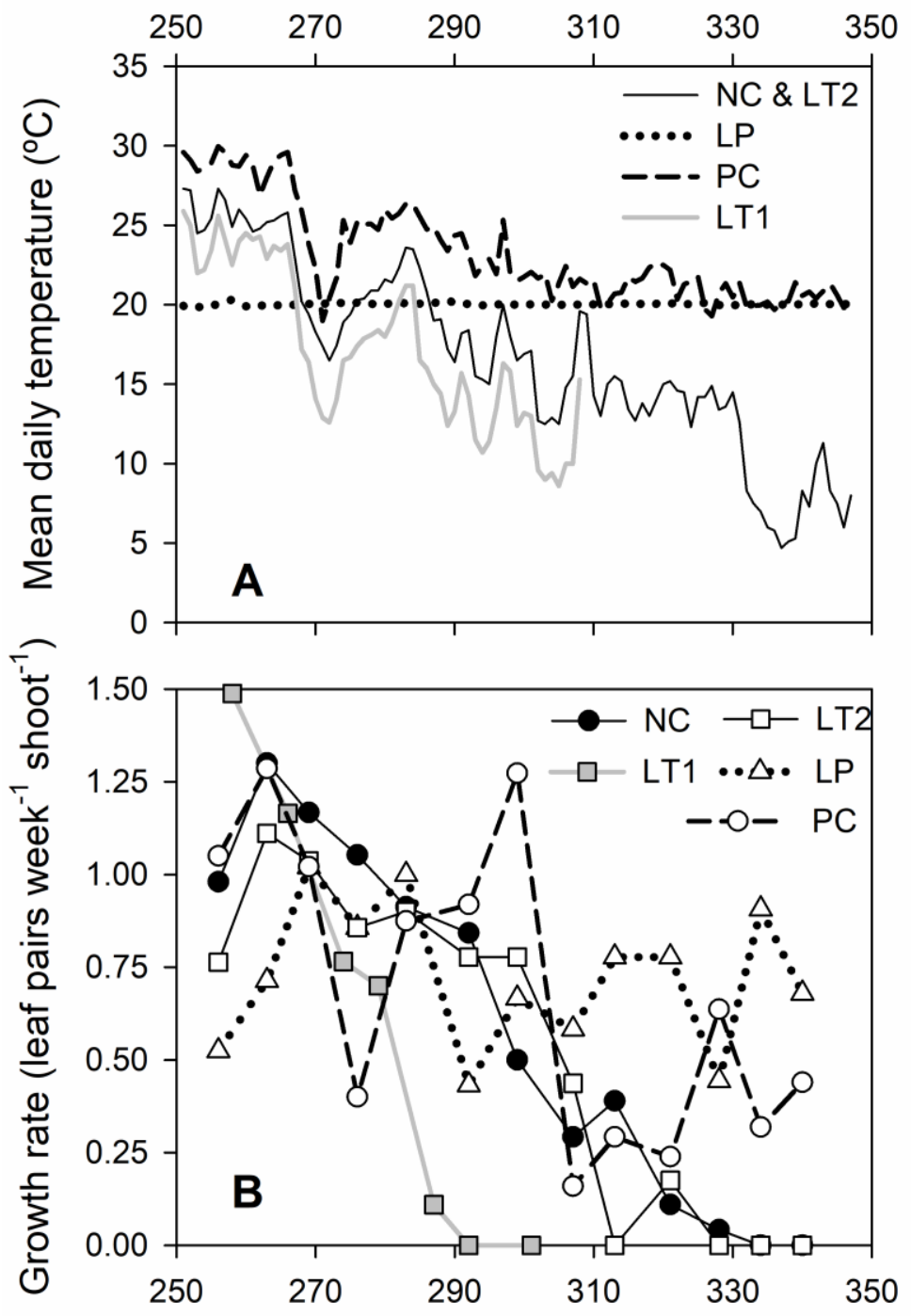

252

Day of year 2012

253 Figure 1: Time course of the mean daily temperature $(\mathbf{A})$ and growth rate $(\mathbf{B})$ throughout

254 Experiment 1 for the different treatments. NC: Negative Control, LT1: Limiting 255 Temperature 1, LT2: Limiting Temperature 2, LP: Limiting Photoperiod, PC: Positive 256 Control. 


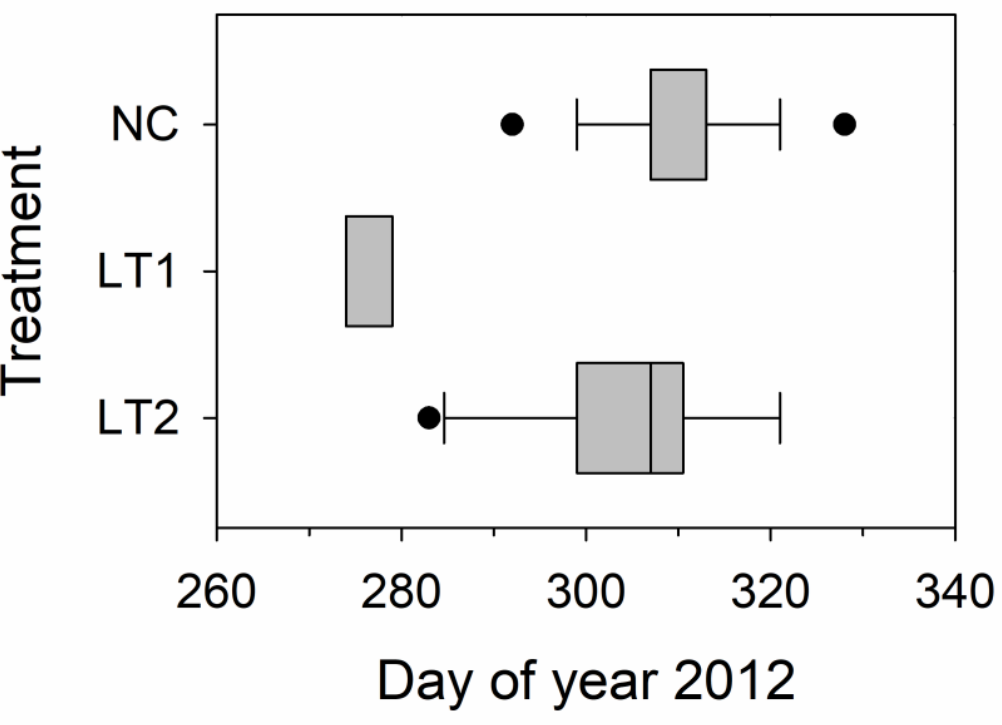

259 Figure 2: Box and whisker plot representing the variability between shoots in the date 260 (day of year) at which the last leaf pair is observed for the three outdoor treatments in 261 Experiment 1 (NC: Cordoba, natural photoperiod; LT1: Espiel, natural photoperiod; LT2:

262 Cordoba, extended photoperiod). The boundaries of the boxes indicate the $25^{\text {th }}$ and $75^{\text {th }}$ 263 percentiles, while the line within the boxes marks the median. Whiskers indicate the $10^{\text {th }}$ and $90^{\text {th }}$ percentiles and the dots represent outliers.

\subsection{Experiment 2}

267 As in Experiment 1, our measurements showed a declining trend in vegetative growth rate as autumn progressed, with the last new leaf pairs being generated before DOY 329 (i.e. November 25) (Fig. 3). Outdoor control plants remained dormant throughout the winter, with vegetative budbreak being noticed around DOY 79 (March 20). During this dormant period, mean daily temperatures were rarely above $15^{\circ} \mathrm{C}$, with an average value

272 of $10.5^{\circ} \mathrm{C}$. Inside the greenhouse, the conditions were maintained relatively stable 273 throughout the winter, with mean daily temperatures around $22{ }^{\circ} \mathrm{C}$ and minimum daily values always above $18^{\circ} \mathrm{C}$ (Fig. 3). 


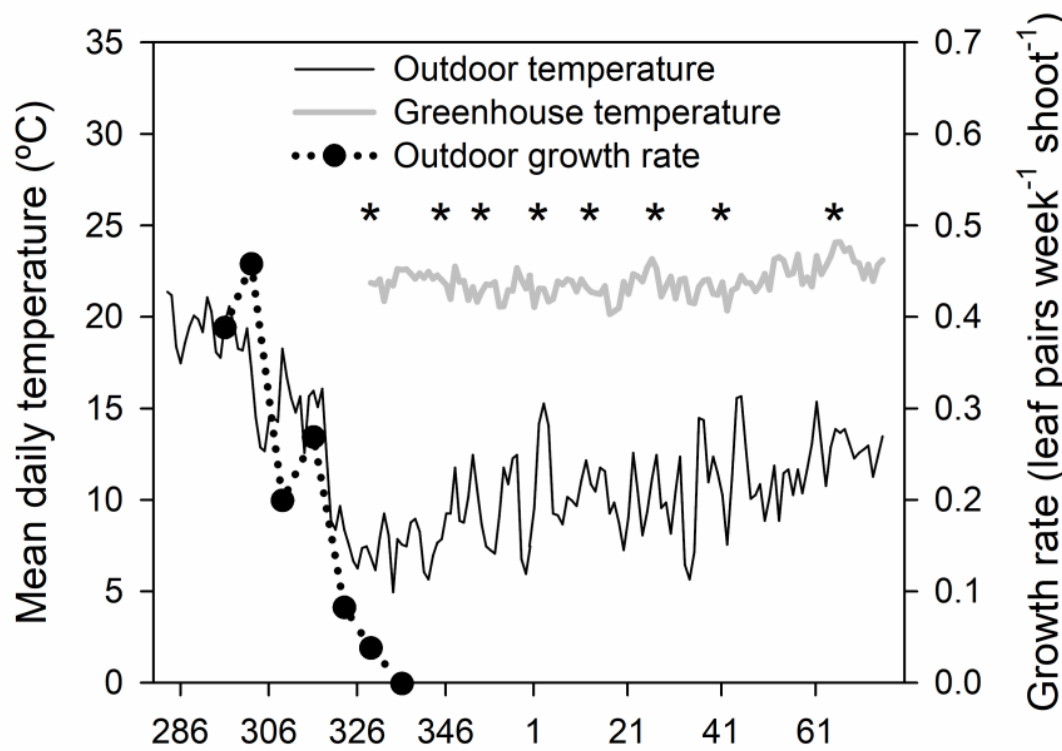

Day of year $2013 / 2014$

Figure 3: Time course of the outdoors (black line) and greenhouse (grey line) mean daily temperature during Experiment 2 and of the monitored autumn growth rate in outdoor plants (dotted line). Asterisks indicate the dates (day of year) at which the different sets of plants were transferred into the greenhouse.

Once placed into the greenhouse, vegetative bud break was observed after two weeks in most of the cases (Fig. 4). The time required to produce the first new leaf pairs was longer (within the third week) and shorter (within the first week) for the sets of plants introduced on DOY 345 (December 11) and DOY 65 (March 6), respectively. Interestingly, there were clear differences between sets in the vegetative growth rates upon budbreak: the later the date of entry into the greenhouse, the higher the rate of leaf appearance following budbreak (Fig. 4). It should be noted that the first and later sets of plants were transferred to the greenhouse very close to the dates at which vegetative growth cessation and resumption, respectively, were observed (Fig. 3). 


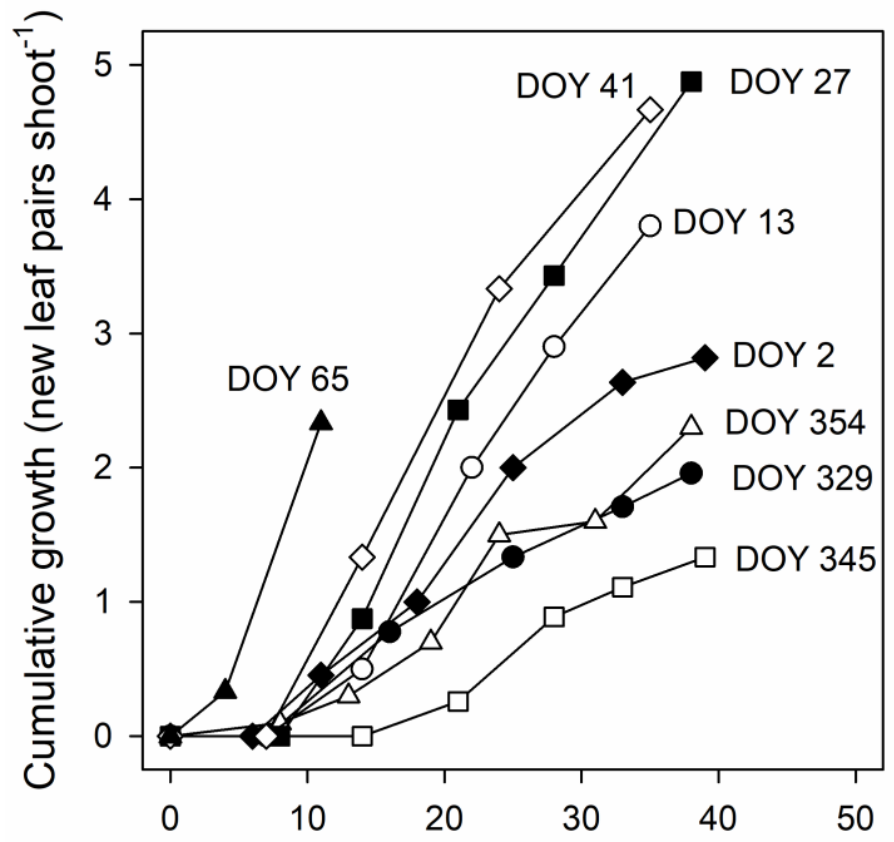

Time since entry into the greenhouse (days)

291

292

293

294

295

296

297

298

299

300

301

302

\subsection{Experiment 3}

The box and whisker plots shown in Figure 5 depict the intra- and inter-cultivar variability found in the dates of growth cessation for the four combinations of location x season studied in Experiment 3. Differences between shoots of the same cultivar were generally very large, exceeding $30 \mathrm{~d}$ between the dates at which the last pair of leaves were observed to appear in some cases. Partially, such large cultivar variability made difficult to establish a consistent ranking between cultivars. In fact, the analyses of variance revealed no significant differences $(\mathrm{P}>0.05)$, except for the comparison between Picual and Arbequina in the dataset of Espiel 2016 (Table 1). 

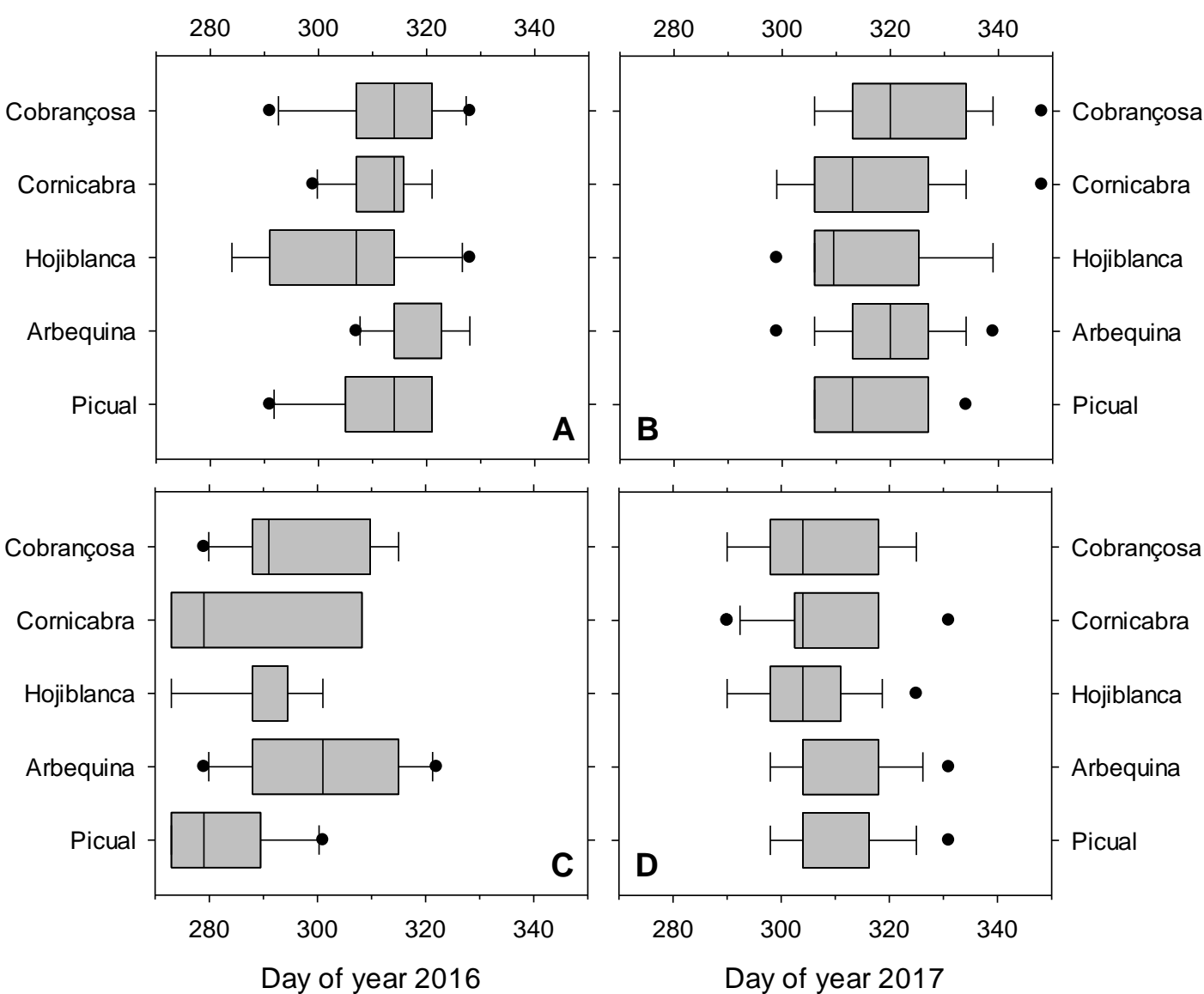

Figure 5: Box and whisker plot representing the variability between shoots in the date (day of year) at which the last leaf pair is observed for the five olive cultivars and the four combinations of site x year: Cordoba 2016 (A), Cordoba 2017 (B), Espiel 2016 (C), Espiel 2017 (D). The boundaries of the boxes indicate the $25^{\text {th }}$ and $75^{\text {th }}$ percentiles, while the line within the boxes marks the median. Whiskers indicate the $10^{\text {th }}$ and $90^{\text {th }}$ percentiles and the dots represent outliers.

312 Figure 6 shows the time courses of mean daily temperature for the four combinations of 313 location $\mathrm{x}$ season as well as the vegetative growth rates measured for the five cultivars in 314 each of those. As in Experiment 1, Espiel was $2-3{ }^{\circ} \mathrm{C}$ colder than Cordoba during the experiments, with both locations showing similar temperature patterns. Besides, the 
316 differences in the meteorological conditions of the autumns of 2016 and 2017 were,

317 generally, small. There were some cultivar differences in leaf appearance rate. For

318 instance, 'Arbequina' and 'Hojiblanca' usually showed, respectively, the highest and

319 lowest leaf appearance rates in the four datasets. However, a consistent ranking between

320 cultivars in this respect was difficult to establish, as some cultivars exhibited high leaf

321 appearance rates in some datasets and low ones in others (e.g. compare 'Picual' in

322 Cordoba 2016 versus the same cultivar in Espiel 2016).

Day of year 2016
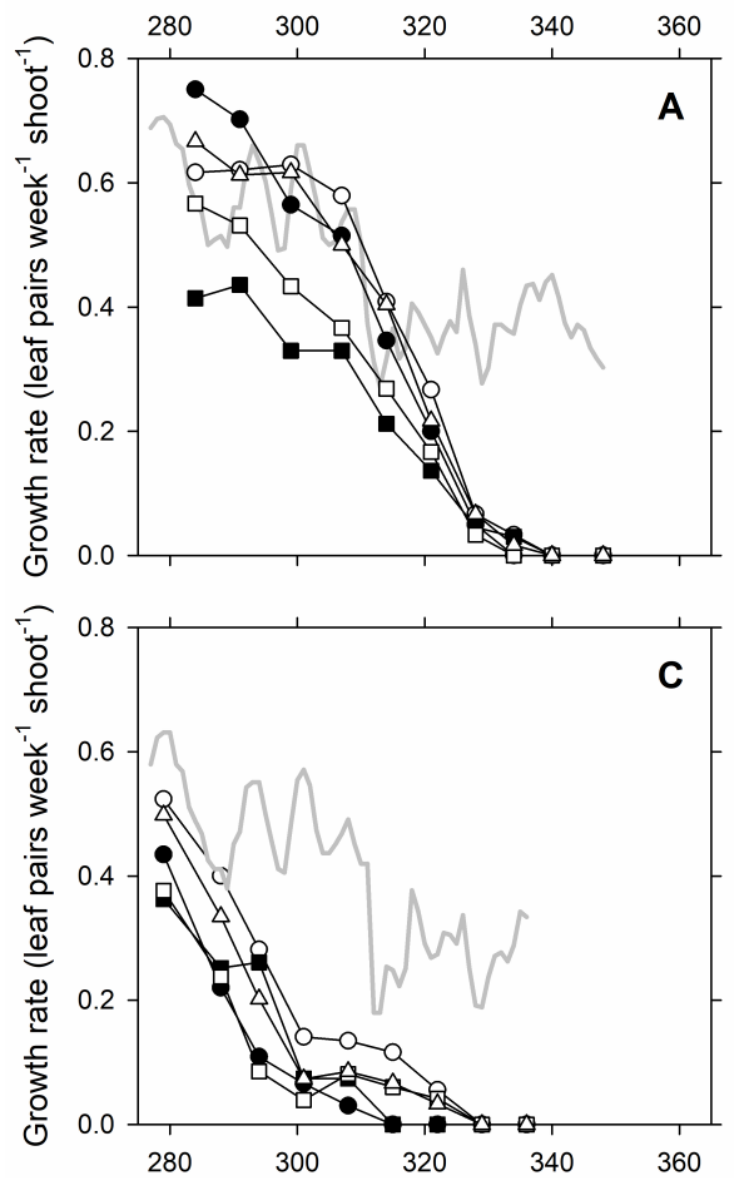

Day of year 2016
Day of year 2017
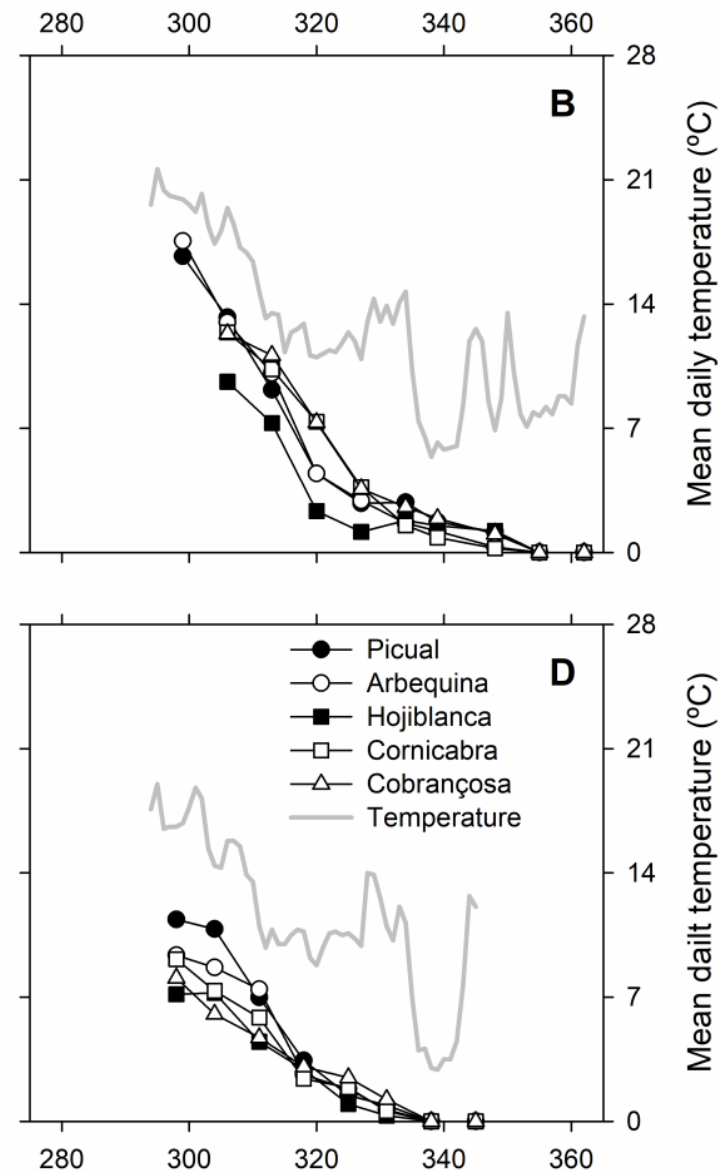

Day of year 2017

324 Figure 6: Time course of observed leaf appearance rates and mean daily temperature in

325 Experiment 3 for the five tested olive cultivars (data on leaf appearance rates correspond 
327 combination of a site and a year: Cordoba 2016 (A), Cordoba 2017 (B), Espiel 2016 (C),

328 Espiel 2017 (D).

329

330 Beyond cultivar variability, the timing of growth cessation differed between datasets (Fig.

3315 and 6 , Table 1). On the one hand, the onset of winter dormancy occurred around one 332 week earlier in 2016 than in 2017 for both Cordoba and Espiel. On the other, leaf 333 appearance ceased earlier in Espiel than in Cordoba, irrespective of the year. The 334 differences between locations were typically between one and three weeks.

\begin{tabular}{lcccc}
\hline Cultivar & Cordoba 2016 & Cordoba 2017 & Espiel 2016 & Espiel 2017 \\
\hline Picual & 310.9 & 314.8 & $281.2 \mathrm{~b}$ & 309.1 \\
Arbequina & 317.5 & 319.0 & $300.5 \mathrm{a}$ & 309.4 \\
Hojiblanca & 305.7 & 315.5 & $289.2 \mathrm{ab}$ & 305.8 \\
Cornicabra & 311.8 & 316.7 & $286.9 \mathrm{ab}$ & 307.9 \\
Cobrançosa & 313.8 & 323.5 & $297.1 \mathrm{ab}$ & 309.3 \\
& & & & 308.3 \\
Average & 311.9 & 317.9 & 291.0 & 1.5 \\
SD (d) & 4.3 & 3.5 & 7.8 & \\
\hline
\end{tabular}
for the five cultivars and four datasets of Experiment 3. Averaged values for the five cultivars and the corresponding standard deviations (SD) are also shown for the four datasets. Means within a column flanked by the same letter are not significantly different at $\mathrm{P}<0.05$. Means flanked by 'ab' are not significantly different to any other mean within the column. 


\subsection{Modelling}

344 The estimates of the parameters in Model 1 were $T_{\mathrm{c}}=14.4{ }^{\circ} \mathrm{C}$ and $\Sigma U_{\mathrm{c}}=160(\mathrm{RMSE}=$

$3453.1 \mathrm{~d}$ ), while those of Model 2 were $T_{\mathrm{c}}=14.5^{\circ} \mathrm{C}, \Sigma U_{\mathrm{c}}=160$ and $a=-0.32(\mathrm{RMSE}=2.5$

346 d). In the validation tests, the models showed RMSE and MAE values below $7 \mathrm{~d}$, while

347 close to zero but positive ones were found for CRM, which indicates that predicted dates

348 of growth cessation tended to be slightly anticipated with respect to the observed dates

349 (Table 2). In all respects, Model 2 performance indicators were better than those of Model

350 1. For instance, EF was 0.64 for Model 1 and 0.91 for Model 2.

351

\begin{tabular}{llllll}
\hline & N & RMSE (d) & EF & MAE (d) & CRM \\
\hline Model 1 & 3 (only 'Arbequina') & 6.14 & 0.64 & 5.00 & 0.017 \\
Model 2 & 3 (only 'Arbequina') & 3.16 & 0.91 & 2.67 & 0.007 \\
Model 1 & 11 (all cultivars) & 8.71 & 0.56 & 7.36 & 0.021 \\
& & & & & \\
Model 2 & 11 (all cultivars) & 4.79 & 0.87 & 4.00 & 0.001 \\
\hline
\end{tabular}

352 Table 2: Performance parameters of Model 1 and Model 2 in predicting the date of growth

353 cessation for $50 \%$ of the shoots monitored belonging to the plants of the cultivar

354 'Arbequina' growing under natural conditions in Espiel in 2012, 2016 and 2017 alone (N

$355=3$, first two rows). Also shown are the performance indicators resulting from

356 considering also the Espiel sets of Experiment 3 corresponding to the remaining four

357 cultivars $(\mathrm{N}=11$, last two rows). RMSE is root mean square error (expressed in days), 
358 EF is modelling efficiency, MAE is absolute error (expressed in days) and CRM is 359 coefficient of residual mass.

361 As an additional test for the models, we derived the performance indicators resulting from 362 adding the observations from the other cultivars used in Experiment 3 in Espiel to the 363 validation set (last two rows in Table 2). The results indicated a slightly lower 364 particularly in the case of Model 1- but still satisfactory predictive power of both models.

\subsection{Additional analysis}

367 Figure 7 depicts the relationship between the leaf appearance rates observed for all the 368 'Arbequina' datasets growing under natural autumn conditions in our experiments and 369 average temperature. When the data pairs involving null or negligible growth $(<0.05$ leaf

370 pairs week $^{-1}$ shoot $^{-1}$ ) were discarded, a robust correlation was found between leaf

371 appearance rate and average temperature $\left(\mathrm{r}^{2}=0.691, \mathrm{P}<0.001\right)$. From the parameters of 372 the linear regression fit, a phyllochron of $94{ }^{\circ} \mathrm{C} \mathrm{d}$ leaf pair ${ }^{-1}$ was deduced, with a base 373 temperature of $11.1^{\circ} \mathrm{C}$. 


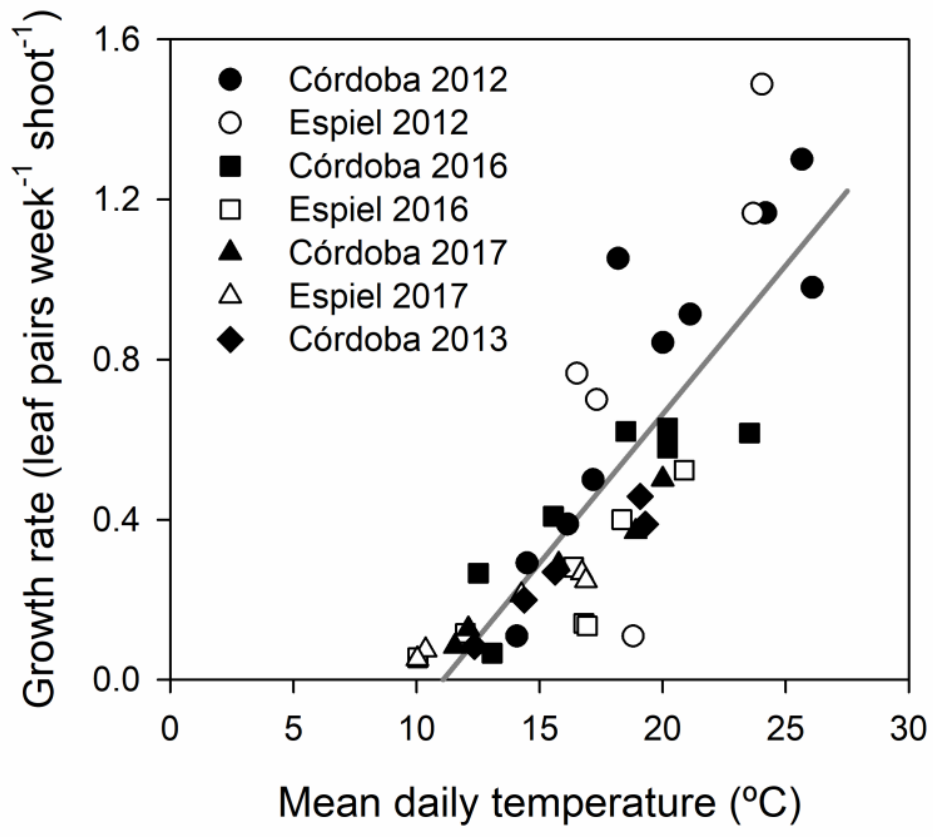

375 Figure 7: Plot of measured leaf appearance rates versus average temperature for the six 376 datasets involving the cultivar 'Arbequina' under natural conditions during the autumns 377 of Experiments 1,2 and 3. The grey line represents a linear regression fit between these 378 two variables discarding the data pairs with leaf appearance rates below 0.05 leaf pairs 379 week $^{-1} \operatorname{shoot}^{-1}\left(Y=0.0744 X-0.8245, r^{2}=0.692\right)$ and including the seven datasets.

\section{Discussion}

Short photoperiod has long been found to be the dormancy-inducing signal in most temperate-zone woody plants (Heide, 1974; Kramer, 1936; Wareing, 1956). In some species like apple, pear or Sorbus spp., however, temperature acts as the main environmental cue triggering growth cessation, while photoperiod plays a negligible regulation role (Heide, 2011; Heide and Prestrud, 2005). Experiment 1 revealed that the generation of new leaf pairs only ceased on the treatments subjected to low temperatures, 
irrespective of the imposed day-length (Fig. 1), which puts olive trees in the same group as the aforementioned Rosaceae species.

One unexpected finding from Experiment 1 was the large shoot variability in the date of growth cessation, which was a common feature in the subsequent Experiments 2 and 3 (Figs. 2 and 5). In the selection of the sample shoots before the proper start of the experiments, we always chose sun-exposed, actively-growing shoots from the upper half of tree crowns, which might suggest that the phenomenon was not originated by differences in shoot typology. In any case, a more thorough exploration of the factors leading to the differences in the onset of dormancy between shoots deserves further research.

Experiment 2 shed some light into the nature of vegetative winter dormancy of olive trees, but it was insufficient to elucidate whether it is controlled endogenously or not. For instance, budbreak occurred in all sets of plants regardless of the date of entry into the greenhouse, which perfectly fits with the hypothesis of ecodormancy. The fact that budbreak did not occur immediately after plants were subjected to the warm greenhouse conditions (it usually took more than one week, Fig. 4) could be seen as an evidence of endodormancy, but it may also be ascribed to a delay between meristem reactivation and visible budbreak (Rohde and Bhalerao, 2007). As an exception, budbreak occurred within the first week in the last set of plants, but it can be argued that their date of entry into the greenhouse (DOY 65 - March 8th) was very close to the date at which budbreak took place in outdoor trees (DOY $79-$ March $20^{\text {th }}$ ).

The differences in leaf appearance rate after budbreak between sets of plants (Fig. 4) could be attributed to different causes (either alone or in combination). On the one hand, in a context of endodormancy, we might speculate about a hypothetical endogenous growth inhibitor factor which is gradually inactivated or removed as winter progresses. 
413 Such factor would not be able to prevent budbreak, but it would still reduce potential 414 growth rate to an extent dependent on the amount of factor present. Although merely 415 speculative, this explanation is inspired on experimental evidence and models (Chuine, 416 2000; Pope et al., 2014; Darbyshire et al., 2016) indicating that upon the end of 417 endodormancy, further chilling accelerates bud growth and the date of bud 418 break/flowering. On the other, the different growth rates might be linked to differences in 419 reserve remobilization. This hypothesis is based on the premise that the assimilates 420 produced during the winter rest period contribute to the initial vegetative flush following budbreak, as suggested by Bustan et al. (2011). Under these circumstances, the later the 422 date at which plants were transferred to the greenhouse, the higher the amount of reserves available for vegetative growth (due to a longer dormant period during which assimilates were accumulated) and, hence, the higher the leaf appearance rate after the entry of plants into the greenhouse. Besides that, it should be noted that, although all the sets of plants were exposed to similar temperature conditions (Fig. 3), the daylength differed between them, as no artificial lighting was applied in this experiment. For example, daylength was $10.4 \mathrm{~h}$ in the set of plants introduced on DOY 41 (February $10^{\text {th }}$ ) and $9.4 \mathrm{~h}$ in those introduced on DOY 354 (December $20^{\text {th }}$ ). A higher number of daylight hours in the later sets of plants might imply higher net photosynthesis on a daily scale. However, given that the maximum differences were around $1 \mathrm{~h}$ (excluding the set of DOY $65-$ March $6^{\text {th }}$ ), the variation of daylength seems insufficient to explain alone the huge observed differences in leaf appearance rates (Fig. 4).

434 Overall, our results suggest that the dormant winter rest state of olive trees can either be associated with an easily-reversible endodormancy or be the result of an ecodormancy that was partially masked in our experiment by the use of reserves in the initial vegetative flush. In our opinion, the occurrence of an endogenous control of dormancy is more 
plausible because olive trees are known to develop cold hardiness to avoid frost damage

439 (Cansev et al., 2009; Villalobos and López-Bernal, 2017). A cold hardy state is unlikely

440 to be compatible with tissues that can resume growth upon the return of favourable

441 conditions (Burr, 1990). In any case, a better understanding of the regulation of dormancy

442 release and vegetative growth resumption in late winter represents a highly desirable

443 target for future research.

444 Hartmann (1953) also suggested that olive trees undergo a slight rest (i.e. endodormant)

445 period after noticing that trees subjected to favourable growing temperatures the entire winter made no appreciable vegetative growth during January in his greenhouse experiments. This observation, however, contrasts with ours, as we did not find any period at which the sets carried to the greenhouse exhibited negligible growth in Experiment 2. One possible explanation for this discrepancy lay in the cooler conditions of Hartmann (1953)'s greenhouse. In this regard, the minimum allowable temperature was set to 12.5

${ }^{\circ} \mathrm{C}$ (versus $18^{\circ} \mathrm{C}$ in our experiment), which might have led average daily temperatures to be fairly near to the threshold that we estimated for leaf appearance in the cultivar 'Arbequina' (Fig. 7). Besides that, Hartmann (1958) measured monthly trunk diameter variations instead of leaf appearance rates, and the response of cambium to temperature might differ from that of the shoot apical meristems.

The findings of Experiments 1 and 2 are of special interest for tentatively evaluating possible impacts of climate change on the seasonal development cycle of olive trees. According to them, in a warmer scenario olive trees would be expected to delay the date of growth cessation while anticipating budbreak, as a consequence of the primary role that temperature seems to play for the regulation of dormancy induction and release. and to an expansion of the vegetative growing season. 
463 With regard to Experiment 3, limited variability in the onset of dormancy was found 464 between the cultivars selected for the study, which included the three most important ones 465 at the world scale in terms of cultivated area ('Picual', 'Hojiblanca' and 'Arbequina').

466 We must acknowledge that the intrinsic low resolution (i.e. one week) and discrete nature 467 of the measurements conducted in this study in combination with the huge shoot 468 variability challenged a clearer definition of the cultivar differences in the date of autumn growth cessation. This does not undermine our results, though, as the measurements were still valuable to conclude that the variability between cultivars was very small, as shown by Figure 5 and Table 1. Conducting additional tests with different olive cultivars to those used in Experiment 3 might still be worthy to identify cultivars with different performances. As a final remark, the present study did not explore cultivar variability in the timing of budbreak, which deserves further research.

The two models presented in this study showed a good performance in the validation test. The fact that EF was well above zero for the two models (Table 2) implies that they provide considerably better predictions of the date of growth cessation than assuming a simple average. Furthermore, the findings of Experiment 3 and the additional test presented in Table 2 suggest that the model predictions might remain rather reliable even if used with a different olive cultivar than 'Arbequina'. However, we must be cautious about its predictive power as well, as the models were calibrated and validated with the 482 limited number of datasets available. The better performance of Model 2 in relation to Model 1 might be indicative of a delaying effect of high temperatures during the chilling accumulation period leading to dormancy induction, as it is assumed to happen for the reproductive development (De Melo-Abreu et al., 2004), but it may also be explained due to the additional parameter implicit in it. Further collection of datasets, preferentially from environmentally-contrasting areas where olive orchards are grown, would be highly 
desirable to test the models and, if required, to improve their calibration or formulating

489

490

491

492

493

494

495

496

497

498

499

500

501

502

503

504

505

506

507

508

509

510

511 more sophisticated models. In the meanwhile, Model 2 has been incorporated into the framework of OliveCan, a recently developed biophysical model of growth, development and yield of olive orchards (López-Bernal et al., 2018), which was missing a more empirically-based criterion for establishing the date at which vegetative growth switches to a passive role as a sink of carbohydrates.

As a final remark, the experimental evidence presented in this study indicates that temperature is the main environmental cue regulating dormancy in olive trees. However, other environmental variables such as humidity or solar radiation might still exert some, albeit limited, influence on dormancy. Besides, the age of the trees (1-3 years old in our experiments) could also be an important factor for the induction and release of dormancy. Exploring the influence of these factors on olive winter dormancy deserves further research.

\section{Conclusions}

The results of this work provide some of the first pieces of the complex jigsaw puzzle of winter dormancy of olive vegetative tissues. In this regard, this study identified low temperature as the environmental signal triggering vegetative growth cessation, determined that the winter rest period is easily reversible by the exposure to warm conditions, showed that there is a limited cultivar variability in the dates at which the growing season ends and presented two simple models with promising predictive power for determining the onset of winter dormancy. Further research aimed to reach a deeper comprehension of the mechanisms regulating dormancy release and to explore the causes of the large shoot variability observed in the dormancy induction patterns would help us 
to complete the body of evidence provided by the present study and serve as a cornerstone

513 for a number of practical applications, including the development of more complete and 514 robust phenological models.

515

\section{Acknowledgements}

517 This work was supported by Ministerio de Economía y Competitividad [grant numbers 518 AGL-2010-20766, AGL-2015-69822]; ERA-NET FACCE SURPLUS [grant number 519 652615, project OLIVE-MIRACLE], the latter co-funded by INIA [PCIN-2015-259]. In 520 addition, AL-B was supported by a postdoctoral fellowship of the 'Juan de la Cierva521 formación' programme funded by Ministerio de Economía y Competitividad [grant number FJCI-2015-24109]. Excellent technical assistance by M. Orgaz, M. González, I.

523 Calatrava, R. del Río and J.L. Vázquez is gratefully acknowledged. We also thank Prof. 524 J.P. De Melo-Abreu for consultation and reviewing the manuscript. The authors have no 525 conflict of interest to declare.

\section{Author contributions}

All authors played a significant role in both the design of the different experiments and the subsequent interpretation and discussion of the data. AL-B and OG-T conducted the experiments. AL-B led out the writing, with significant contributions from all co-authors.

\section{References}

Arora, R., Rowland, L.J. and Tanino, K., 2003. Induction and release of bud dormancy in woody perennials: a science comes of age. HortScience 38 (5), 911-921. 
Barranco, D., Ruiz, N. and Gómez-del Campo, M., 2005. Frost tolerance of eight olive cultivars. HortScience 40 (3), 558-560.

Burr, K.E., 1990. The target seedling concepts: bud dormancy and cold-hardiness. in: Rose, R., Campbell, S.J., Landis, T.D. (Eds.), Proceedings of the Western Forest Nursery Associations, USDA For. Serv. Gen. Tech. Rep. RM-200, Fort Collins, pp. 79-90.

Bustan, A. et al., 2011. Role of carbohydrate reserves in yield production of intensively cultivated oil olive (Olea europaea L.) trees. Tree Physiol. 31 (5), 519-530.

Cansev, A., Gulen, H. and Eris, A., 2009. Cold-hardiness of olive (Olea europaea L.) cultivars in cold-acclimated and non-acclimated stages: seasonal alteration of antioxidative enzymes and dehydrin-like proteins. J. Agric. Sci. 147 (1), 51-61.

Chuine, I., 2000. A unified model for budburst of trees. J. Theor. Biol. 207, 337-347.

Darbyshire, R., Pope, K.S., Goodwin, I., 2016. An evaluation of the chill overlap model to predict flowering time in apple tree. Sci. Hortic. 198, 142-149.

De Melo-Abreu, J.P. et al., 2004. Modelling olive flowering date using chilling for dormancy release and thermal time. Agric. Forest Meteorol. 125 (1-2), 117-127.

FAOSFAT, 2017. http://www.fao.org/faostat/en/\#data (accessed 10 July 2019)

Haberman, A. et al., 2017. A possible role for flowering locus T-encoding genes in interpreting environmental and internal cues affecting olive (Olea europaea L.) flower induction. Plant Cell Environ. 40 (8), 1263-1280.

Hartmann, H., 1953. Effect of winter chilling on fruitfulness and vegetative growth in the olive, Proc. Am. Soc. Hortic. Sci. 62, 184-190.

Hartmann, H. and Porlingis, I., 1957. Effect of different amounts of winter chilling on fruitfulness of several olive varieties. Botanical Gazette 119 (2), 102-104.

Heide, O.M., 1974. Growth and dormancy in Norway spruce ecotypes (Picea abies) I. Interaction of photoperiod and temperature. Physiol. Plant. 30 (1), 1-12.

Heide, O.M., 2011. Temperature rather than photoperiod controls growth cessation and dormancy in Sorbus species. J. Exp. Bot. 62 (15), 5397-404. 
Heide, O.M. and Prestrud, A.K., 2005. Low temperature, but not photoperiod, controls growth cessation and dormancy induction and release in apple and pear. Tree Physiol. 25 (1), 109-114.

Kramer, P.J., 1936. Effect of variation in length of day on growth and dormancy of trees. Plant Physiol. 11 (1), 127-137.

Larcher, W., 1970. Kalteresistenz und uberwinterungsvermogen mediterraner Holzpflanzen. Ecol. Plant, 5, 267-85.

López-Bernal, A. et al., 2018. OliveCan: a process-based model of development, growth and yield of olive orchards. Front. Plant Sci. 9 (632).

Miyasaka, S.C. and Hamasaki, R.T., 2016. Promising olive cultivars for oil production in Hawaii. HortTechnology 26 (4), 497-506.

Pope, K.S., Da Silva, D., Brown, P.H., DeJong, T.M., 2014. A biologically based approach to modelling spring phenology in temperate deciduous trees. Agric. For. Meteorol. 198-199, 15-23.

Rallo, L. and Martin, G., 1991. The role of chilling and releasing olive floral buds from dormancy. HortScience 26 (6), 751-751.

Ramos, A., Rapoport, H.F., Cabello, D. and Rallo, L., 2018. Chilling accumulation, dormancy release temperature, and the role of leaves in olive reproductive budburst: Evaluation using shoot explants. Sci. Hortic. 231, 241-252.

Rapoport, H.F. and Moreno-Alías, I., 2017. Botánica y morfología, in: Barranco, D., Fernández-Escobar, R., Rallo, L. (Eds.), El cultivo del olivo. Mundi-Prensa, Madrid, pp. 35-64.

Rohde, A., Bhalerao, R.P., 2007. Plant dormancy in the perennial context. Trends Plant Sci. 12(5): 217-223.

van der Schoot, C. and Rinne, P.L., 2011. Dormancy cycling at the shoot apical meristem: transitioning between self-organization and self-arrest. Plant Sci. 180 (1): 12031.

Villalobos, F.J., López-Bernal, A., 2017. Clima, in: Barranco, D., Fernández-Escobar, R., Rallo, L. (Eds.), El cultivo del olivo. Mundi-Prensa, Madrid, pp. 213-250. 
592 Wareing, P., 1956. Photoperiodism in woody plants. Annu. Rev. Plant Physiol. 7 (1), 593 $191-214$. 